\title{
POLYNEURITIS IN HAEMOCHROMATOSIS
}

\author{
EDWARD JaRRETT, M.D., M.R.C.P. \\ Consultant Physician, Dorset County Hospital, Dorchester, Dorset
}

\author{
ANTONy BarTer, M.B., D.Obst.R.C.O.G. \\ General Practitioner, Bridport, Dorset
}

\section{Case Report}

A male taxi-driver, aged forty-seven, was admitted to the Dorset County Hospital on 7.9.60. He was a diabetic of five years standing on $180 \mathrm{~g}$. of carbohydrate and 80 units of lente insulin daily. Following an attack of diarrhoea and vomiting he gave a five days' history of increasing weakness in the legs.

Examination. He was thin, slightly icteric, with sparse axillary and pubic hair, small atrophic testes and multiple pigmented needle-track marks on the lower abdomen and thighs. The liver was large and hard, and the spleen just palpable. He had a flaccid weakness of both legs with tender muscles and absent knee and ankle jerks. This subsequently developed into a frank paraplegia. There were no sensory changes during the early stages.

Investigations. Blood count: $\mathrm{Hb} 88 \%$, $\mathrm{MCHC} 36 \%$, PCV $36 \mathrm{~mm}$., ESR $12 \mathrm{~mm}$. (Wintrobe). Icteric Index 20 units, wbc 12,900 (neutrophils $75 \%$, monocytes $9 \%$, lymphocytes $16 \%$, marked toxic changes in the neutrophils). Prothrombin time $50 \%$ of normal. The blood culture grew $E$. Coli.

The serum iron was $440 \mu \mathrm{g} . / 100 \mathrm{ml}$., the S.G.P.T. was 372 units, and the serum bilirubin $2.9 \mathrm{mg}$. $/ 100 \mathrm{ml}$., (direct $1.3 \mathrm{mg} . / 100 \mathrm{ml}$.). The total protein was $5.7 \mathrm{~g}$. / $100 \mathrm{ml}$., of which the albumin was markedly decreased and the alpha-2 and gamma globulin increased. The CSF was slightly xanthrochromic; there were 34 wbcs (mainly polymorphonuclears), and the protein was $15^{\circ}$ $\mathrm{mg}$./ $100 \mathrm{ml}$. A diagnosis of hæmochromatosis and acute polyneuritis was made.

Progress and Treatment. His temperature rose to
102. $5^{\circ} \mathrm{F}$ and his pulse to $150 / \mathrm{min}$. and there were signs of early meningitis. He was treated with prednisolone in high dosage, chloramphenicol and later tetracycline. His condition deteriorated, and he died on 24.9.60.

Autopsy Report. There were bilateral pleural effusions. The liver was enlarged and weighed $1,652 \mathrm{~g}$.; it was very firm and showed irregular cirrhosis; there were one or two small abscesses. The spleen was enlarged, weighing $364 \mathrm{~g}$. It was firm, and on section showed decreased prominence of the follicles. The pancreas was firm and slatey-grey in colour. There was a turbid ascites present. Histology showed heavy deposits of iron in the cardiac muscle and slight deposition in the zona glomerulosa of the adrenal cortex, the pars anterior of the pituitary gland and in the dermis at the site of previous insulin injections. There was no histological abnormality found in the spinal cord, but the peripheral nerves were not examined. The pathologist's cause of death was:-
(i) heart failure,
(ii) E. coli septicæmia,
(iii) hæmochromatosis.

\section{Comment}

A striking sign which we have not seen reported elsewhere was the pigmentation along the injection tracks. The rapid progression of the polyneuritis was quite unlike that normally met with in diabetic neuropathy. After reading Melnick and Whitfield's paper (1962) we feel that there is a possibility of a direct link between the polyneuritis and the hæmochromatosis.

\section{REFERENCE}

Melnick, S. C., and Whitfield, A. G. W. (1962): Polyneuritis in Hæmochromatosis, Postgrad. med. F., 38, 580.

\section{CONGENITAL PENILE SINUS}

\author{
Christopher Wastell, F.R.C.S. \\ Department of Surgery, Westminster Hospital
}

A ventral mid-line sinus of the penis is an unusual condition resulting, possibly, from a failure of fusion of the urethral crests. It is related to the more commonly occurring mid-line congenital cyst and nearly 50 examples of these two anomalies have been reported to date (Thompson, 1959).

\section{Case Report}

A 43-year-old circumcised man sought advice about two superficial sore lesions on the under surface of his penis and scrotum. These had been present for two weeks and had discharged a small quantity of pus. Seven years previously he had noticed a pore on his penis from which it was possible to express a chalky material. At this time his doctor had incised a superficial infective lesion close by this orifice. On examining the penis and scrotum (Figs. I and 2) there were two mid-line infected lesions, one being at the peno-scrotal junction and the other $5 \mathrm{~cm}$. posterior to it. In addition there were two sinuses, one, $2 \mathrm{~cm}$. in length, extended along the proximal third of the shaft of the penis from an orifice situated in 